\title{
The Social Media Communication of Hungarian County Seats: Facebook, Instagram, and YouTube Presence
}

\author{
Árpád PAPP-VÁRY ${ }^{1}$ \\ Alexandra SZÜCS-KIS ${ }^{2}$ \\ Budapest Metropolitan University \\ Budapest, Hungary \\ ${ }^{1}$ e-mail: apappvary@metropolitan.hu \\ ${ }^{2}$ e-mail: szucs.kis.alexa@gmail.com
}

\begin{abstract}
The communication toolkit of urban marketing has changed significantly in recent years, with online solutions and social media becoming the focus of attention besides (and, in a way, instead of) classic offline tools. In our study, we explore how this toolkit can be effectively applied to cities and how cities should communicate through different platforms. For this purpose, we have created a kind of social media tutorial regarding Facebook, Instagram, and YouTube. In our own primary research, we used data from the first quarter of 2021 to investigate the presence of Hungarian county seats on the abovementioned three platforms. For this purpose, in addition to the usual social media data, such as page likes, subscribers, number of views, or even the activity rate, we created a much more complex, professional but also - inevitably - somewhat subjective analysis system. It would be also worthwhile for other cities to use this criteria system as a checklist or to adopt good practices from the cities at the top of the list.
\end{abstract}

Keywords: Hungarian county seats, social media communication, Facebook, Instagram, YouTube

\section{The Most Important Social Media Tools in City Marketing}

In the first part of our study, we will briefly analyse the different social media platforms, and then we will discuss the most important information about them in detail. Last but not least, we will show how cities should use the specific tools. In 
each subsection, we tried to refer to the characteristics of each platform by using a witty adjective in the title.

\subsection{Facebook - "The Online Diary"}

Facebook is one of the most important global social media platforms (and, in many ways, the most important one), which has led to a whole new set of user habits (Klausz, 2011: 102).

It has become the third most visited site in the world (with only Google and YouTube ahead), and its mobile interface is the second most downloaded application in the world. According to research data from early 2021, the number of active users per month is currently 2.74 billion out of the 7.64 billion inhabitants of the Earth. Facebook users spend an average of 34 minutes a day browsing the site, liking an average of 12 posts, and clicking on 12 ads per month. The pandemic situation has also influenced Facebook trends, making the site even more popular and resulting in a $50 \%$ increase in the number of views of live events such as fitness classes and lectures (Newberry, 2021a).

Facebook is a platform for young people, middle-aged people, and the older generation as well. According to a US survey, $64 \%$ of $12-34$-year-olds, $74 \%$ of $35-54$-year-olds, and $52 \%$ of $55+$ year-olds, meaning $63 \%$ of the total population (13 years and over), were regular users in 2020 (Newberry, 2021a).

Now let us look at the possible use of Facebook in the case of cities. If we look at a city's Facebook page, the first thing we are likely to notice is the cover and profile pictures of the page. You can set a video as the cover image, and the profile picture is usually the logo or coat of arms of the city. The page is then divided into two vertical sections. The main content (about, photos, etc.) and informative data about the community (number of page likes) are displayed on the left, while the timeline is displayed on the right - you can navigate between the menu items to change the content displayed at any time. It is important for a city to use as many relevant features as possible, as each gives the user an extra opportunity to get information on the topic. It is very important to fill in the details of the About section (e.g. address, phone number, website, other social networking sites), and it is also an opportunity to explain your purpose and story in more detail.

For Facebook pages, it is the quality and content of the published posts, photos, and videos that matter most, as this is what users consider in deciding whether or not they are interested in the page, i.e. whether or not they like it. According to statistical analysis in 2020, Facebook pages share an average of 1.55 posts per day, $55.6 \%$ of which are photos, $22.2 \%$ are video creatives, $18.5 \%$ are link posts, and $3.6 \%$ are plain text content (Newberry, 2021a). However, in addition to increasing the number of page likes, it is also important to pay attention to maintaining the activity rate since it is useless for a user to follow a city's page if he or she does 
not see any posts or the profile or its administrator does not respond to comments at all. The average activity rate generated by Facebook posts is $0.18 \%$, and below 10,000 page likes it is $0.52 \%$. For video content, the average is $0.26 \%$ according to the latest statistics (Newberry, 2021a).

In addition to the timeline, Facebook offers many other options for users. For example, the Stories feature (i.e. content available for just 24 hours) is used by an average of 500 million people a day. In addition, one of the most popular services is the Messenger messaging platform, which is used by 1.3 billion people - many of whom are not otherwise active on Facebook. Last but not least, there are Facebook Groups, used by 1.8 billion users, which provide an excellent opportunity for community building (Newberry, 2021a). For most cities, users create the groups themselves, but it is also worth being present in some form in these, as there are many questions and needs that can be directly explored, and it can be useful to share up-to-date information within the groups.

In the business market, most companies prefer to let experts take care of the day-to-day tasks and employ an agency to produce quality content, as this kind of creativity and expertise is needed to stand out in a saturated market - but this is still not a popular solution for cities, where most things are done in-house rather than outsourced. But content can still be enriched, for example, by publishing GIFs (moving or animated content) or memes (funny images or videos that spread quickly on platforms) or by running games and competitions.

However, a page with perfect content is still not useful if only a few people know that it exists. This is addressed by the platform's ads manager, which offers several different features for pages. In Facebook's heyday, it was possible to achieve good results on the platform without paid advertising, that is, only through organic (unpaid) promotion. However, the effectiveness of this has been declining in recent years, as existing followers are not necessarily aware of new content any more (mainly due to changes in the algorithm and the increasing amount of content and, of course, Facebook's business model). Examples of the types of ads that can be used include, but are not limited to, fan-gathering ads (aimed at attracting new visitors to the page), highlighting posts (which can also help to gather reactions), and ads to promote events or encourage downloading an app. In addition to these, for those with a website, it can be a useful advertising feature to run trafficgenerating or conversion ads, which can achieve very impressive results. In the latter case, i.e. conversion advertising, the user completes a goal such as making a purchase or downloading something. Examples include advertisements promoting summer concerts in a city, where it only takes a few clicks to buy tickets (in this case, the conversion goal is to buy tickets). In addition, the ad manager aggregates the results of the campaigns so that they can be easily analysed and optimized according to different criteria and metrics. 


\section{City Marketing Tutorial for Facebook}

- Overall, we can say that Facebook is currently an unmissable opportunity for all cities, as it allows them to quickly gain real, relevant page followers with whom they can communicate continuously through the platform. Creating an official page and filling it with content is therefore the first step to a social media presence.

- When planning and designing posts, it is worth bearing in mind the use of content types that can boost activity, such as videos, GIFs, and games.

- Through the page, you can provide content not just for one but almost all of your target groups, even thematically - including local residents, entrepreneurs, NGOs, but also tourists or investors.

- From a long-term strategic point of view, it is easy to show the existing uniform identity by displaying certain permanent elements and colours through the creative content of the page.

- In addition to organic content, it may be also useful to start increasing paid appearances, as Facebook's ad manager can deliver impressive results for a very small budget in terms of activity, page likes, and other conversion goals.

- Along with page management, it is worth exploring existing Facebook groups, and if there are none, an official group can be created.

\subsection{Instagram - "The Digital Photo Album"}

Instagram was launched in 2010, when the app was only available on iPhone devices. The platform quickly caught on with users because it focuses on visual content rather than text. Therefore, it provides relaxing entertainment with a focus on pictures and videos - usually with short captions although longer captions are now a trend again.

According to data from early 2021, the number of monthly active users had already exceeded 1 billion. In addition, content posted in stories are followed by 500 million people a day, making Instagram the sixth most visited website today. The platform's users are mainly young people, spending an average of 30 minutes a day consuming content. The various business pages/profiles publish an average of 1 post per day on the platform (Newberry, 2021b).

In his 2019 work on Instagram marketing, Jack Gary highlights the percentage of committed users reached by the platform (those who like, comment, share, or follow the page, i.e. show some activity in connection with the content), which he complements by mentioning a research by Forrester. It shows that the activity rate on Instagram is 58 times that of Facebook and 120 times that of Twitter (Gary, 2019: 11).

As the platform is dominated by images, content consumption is also faster than on Facebook - adapting to the online habits of the younger generation. In addition to the continuous scrolling of images, the platform now offers a range 
of other features. These include stories (which are displayed by the application for 24 hours), GIFs and various animated stickers, voting, internal messaging, countdown, etc. Furthermore, you can create highlights, which are stories that you do not want to lose after a day, so you can keep them using some sort of grouping (e.g. travel, restaurants, work). You can also give them a name so that everyone understands the basis of sorting. Also, there are applications that let you create a cover page with the same style for different groups of Instagram highlights, giving your account a unique identity. Another useful feature is the live feed, which appears in the stories but is prominent during the broadcast. The latest feature is $I G T V$, which allows the posting of videos longer than 30 seconds on the platform, making it possible to operate it as a vlog (or video blog).

Instagram can be managed together with Facebook ads from an advertising perspective, but in addition to the news feed, there is also the option to appear between stories or to display the same content on both Facebook (including Messenger) and Instagram through an ad. However, duplicating content is not recommended, as we are targeting different audiences on different platforms, and it can be boring for those who are present on both platforms to see the same thing.

\section{City Marketing Tutorial for Instagram}

- Instagram is a symbol of a new era in our world, which has become an indispensable element of the online presence of cities. With its many features, the platform gives us the opportunity to show the best of your city through images and short videos, both to residents and to external audiences, especially tourists.

- Although Instagram has a high activity rate compared to other platforms, it is still worthwhile to use content types that tend to generate higher activity, such as videos and GIFs.

- Besides sharing posts, it is useful to remember the importance of stories and highlights, where you can share daily updates with your followers, making their connection to the city even more personal.

- Considering aspects of developing the city identity, it is also useful to use certain permanent elements and colours in the posts, stories, and cover pages of the highlights on this platform.

- Consistent use of hashtags is of paramount importance, as unique hashtags can easily spread among users, generating traffic for the city's page, while more popular ones may attract new users to the page.

- In addition to organic content, it is relatively easy to create an ad on Instagram, but only the content can be highlighted in this case. Although there is no direct way to increase the number of followers, it is possible to encourage users through posts with a little creativity to follow you on the platform. 


\subsection{YouTube - "The TV of the Internet"}

The YouTube video sharing platform was launched in 2005 and caught on with users very soon. By 2021, YouTube has become the second most visited website in the world (after Google Search) and the second most popular social media platform (after Facebook). The number of active (logged in) users per month had exceeded 2 billion by the beginning of the year - but it is important to note that the site can also be used without a login. Surveys show that the average time spent on the platform by people aged 18+ is 42 minutes a day (Newberry, 2021c).

It is important to note that anyone can become a content producer on the platform, as registration and publishing content is free. In short, the process of creating and sharing a video is as follows: once a topic has been dreamed up, a video can be created in a variety of ways, with infinite variations depending on the imagination and possibilities of the creator. Once the shot is ready, all you need is an eye-catching title, description, appropriate tags, and a selected index image, or thumbnail image - the latter is what users see as a home image, so it is a good idea to choose a telling one. That is all it takes to post a video, but the YouTube platform offers much more than that. For example, you can create a socalled transcript, which is a very useful option for users to see parts of the video in a table-of-contents-like way, preview the content, and jump directly to the part of the video they are interested in. For those considering not only a one-off share but also a continuous channel, the closing image is a great option, which can be displayed in the last 5-20 seconds of videos, regardless of video length. This is therefore a recommendation to the user regarding interesting topics and where to click next.

If you want to run a well-functioning channel, the Creator Studio interface provided by YouTube makes it easy to track the growth of the channel and the popularity of different topics through various analytics. The platform really does offer more than traditional television, as it not only produces content but also allows for constant and mutual communication with consumers through comments and the building of an active and interested community.

\section{City Marketing Tutorial for YouTube}

- It may also be worthwhile for cities to publish videos on different topics, as they can further increase user interest, deepen the relationship they have established, and easily share the published content on other platforms or for advertising purposes.

- Various city events, commemorations, graduations, concerts, or other events may all be excellent topics for video content. Users may also consider image videos for tourists, showing local attractions and places of interest, or they can 
produce ones for investors, focusing on the potential of the city, or even videos combining both aspects.

- While the examples above require more preparation, you can also make videos that require less investment and less post-production. This could be an interview with a local celebrity or an online presentation/broadcast of a concert. The possibilities of the platform are endless, limited only by the creativity and financial means of the marketing team.

- In addition to planned video content, you may also want to experiment with live broadcasts, whether it is the mayor's office hours or the coverage of an event.

- Visual identity elements are also useful in this case, for example through the use of index images.

- When publishing content, it is not a good idea to leave out solutions that require less work such as the closing image, the descriptive section, and the transcript.

\section{An Examination of the Online Presence of County Seats in Hungary}

After getting acquainted with the main characteristics of each social media platform and the arguments for their use by cities, in the next section we will focus on the presence of Hungary's county seats on these platforms.

It is important to note that we have not analysed the county seats in terms of their attractions, culture, economy, or even resources, nor even their city marketing in general. All we were interested in was how much use they make of the listed tools and opportunities of social media communication.

In addition to the usual social media data, such as page likes, subscribers, views, or activity rate, we have also created a much more complex set of criteria. This system is, of course, professionally based, but it is also somewhat subjective, inevitably - however, the scoring system is not subjective, allowing a uniform comparison of social media communication by the county seats.

This analysis is based mostly on yes/no questions, with a negative answer of 0 and a yes answer of 1 (criteria partially met) or 2 (criteria met). In addition, the criteria also include some multi-point items that could not be asked in the form of a yes/no question - for example, the one regarding the frequency of posts. The scores obtained were finally summed up and used to produce a ranking of the cities. Once again, it is important to stress that all these preference systems, even if professionally based, are inevitably subjective. However, the same can be said of other city brand rankings, and it is no coincidence that no two rankings have ever produced the same result. 
Our measurement tool was therefore primarily the scoring table we had created, in which we collected the scores by criteria, as well as figures for other data of the page (page views, average number of likes/post, activity rate). In creating the system, we tried to take into account as many useful features and options as possible and to evaluate the regularity, variety, and quality of the content of the posts. As it is not possible to combine the different data, we ultimately produced a number of rankings, which we then tried to evaluate together.

For sampling purposes, we first collected the cities and their platforms to be examined. It is important to note that the analysis focused strictly on the central pages and did not include tourism-related social media profiles or city profiles linked to local news outlets and press organs. We are confident that our research has thus been able to provide a complete coverage of each social media platform of the county seats. If any platform of a city is not included in the analysis, that is, of course, the responsibility of the authors - in that case, we were not attentive enough while gathering information.

The results related to the social media pages of the county seats have been added one by one to the table mentioned above. The data was thus collected in a summary table so that we could easily rank the cities according to the given criteria later on.

The cities surveyed were Békéscsaba, Debrecen, Eger, Győr, Kaposvár, Kecskemét, Miskolc, Nyíregyháza, Pécs, Salgótarján, Szeged, Székesfehérvár, Szekszárd, Szolnok, Szombathely, Tatabánya, Veszprém, and Zalaegerszeg. In total, we analysed the social media presence of 18 cities, i.e. rural county seats. Budapest was deliberately left out, as it is difficult to compare the capital with the above-mentioned cities.

The platforms examined were Facebook, Instagram, and YouTube. The covered period was 1 January 2021-31 March 2021 (3 months in total).

\section{An Analysis of the Facebook Pages of County Seats}

\subsection{Presentation of the Analytical Framework}

Facebook offers a wealth of opportunities for pages, both in terms of presence and community building, as well as advertising. The above framework includes elements that can be found in the settings of Facebook pages and can easily be completed with a little effort, thus increasing the quantity and quality of content on the page.

Each page has a unique link that is automatically generated by Facebook when it is created. It is worth changing this, as it makes the page more searchable and, if a user links to it, it will look nicer with an edited link (e.g. www.facebook. com/Békéscsaba-Megyei-Jogú-Város-181417988538630/ vs. www.facebook.com/ debrecenvarosa/). Just as in the case of various businesses, you may also want to 
set the coat of arms or logo of the settlement as the profile picture of the city (and display it on the creatives of your posts). This is necessary from the users' point of view because they will mainly see the posts on their timelines, and the logo can make the page much easier to identify, not to mention branding, which is also based on it in a sense. Setting the cover image is quite essential, as its absence is easily noticed by users. The cover is no longer just a picture, as it can also be a gallery of images or a video (the latter is more likely to grab the attention of users, so we gave +1 point to examples where it was used).

Table 1. Analytical framework - Facebook

\begin{tabular}{|c|c|}
\hline Criteria & Score \\
\hline Custom username set (link) & 1 \\
\hline The profile picture is the city's coat of arms or logo & 1 \\
\hline It has a cover image & 1 \\
\hline It has a video as cover image & 1 \\
\hline Contact details are filled in (partially/fully) & 2 \\
\hline Click-through option to other social media channels & 1 \\
\hline There is an events tab & 1 \\
\hline Post share (irregular: 1 , weekly 1: 2 , weekly $2: 3$, weekly $3+: 4$, daily $3+:-1$ ) & 4 \\
\hline Utilization of functions, updates, news tracking (occasional/regular) & 2 \\
\hline Use of image galleries/montages/albums (sometimes/regularly) & 2 \\
\hline Activity posts (occasional/regular) & 2 \\
\hline Video posts (occasional/regular) & 2 \\
\hline Traffic diversion link posts (sometimes/regularly) & 2 \\
\hline Carousel posts (occasional/regular) & 2 \\
\hline Use of own images (sometimes/regularly) & 2 \\
\hline Spelling & 1 \\
\hline Emoji usage & 2 \\
\hline Community management & 1 \\
\hline Number of likes (end of month 3) & - \\
\hline Number of posts ( 3 monthly) & - \\
\hline Average number of likes and reactions per post & - \\
\hline Average number of comments per post & - \\
\hline Average number of shares per post & - \\
\hline Engagement rate (average) & - \\
\hline TOTAL & 30 \\
\hline
\end{tabular}


We then looked at the About tab, where there are several options that can be filled in. This includes, for example, filling in contact details and the option to click through to other platforms. You can also create various events on behalf of the page, which you can organize into a chronological list within the page, under the Events tab in the header. This can be particularly useful for events, as it allows the user to view upcoming events in one place.

After an examination of the settings, we looked at the posts of the pages, which we narrowed down to one quarter (1 January-31 March 2021). The regularity of the posts shared is a key issue in managing any platform, so we have scored this differently. A score of 1 point was awarded if posts were shared irregularly, 2 points if one post per week was regularly shared, 3 points if two posts per week were shared, and 4 points if three or more posts per week were shared. However, this should not be overdone either, so 1 point was deducted for results exceeding 3 posts per day. It is important that the posts published should be good not only qualitatively but also quantitatively, so we have focused our attention on the content of the posts after the number of posts. We examined whether the page was making use of the currently available post types (e.g. poll, 3D post) and whether it was following the trends. We also looked at whether the page used a gallery feature, whether there were video/GIF and link posts, and whether there were activity posts. We also monitored the use of own images (by own we do not mean the posting of stock images that can be bought and used freely, which make the page boring) and community management. In terms of the text of the posts, points were given for spelling and the use emoticons, which eases the texts and makes them social media friendly.

In the final section, we collected data that were used to create a separate ranking, as they do not characterize the quality of the page in themselves but are important benchmarks alongside the other criteria. Thus, we recorded the number of page visitors, the total number of posts for the three months under review, and the average number of likes, comments, and shares. These were then used to calculate the engagement rate: [(likes + comments + shares) / post] / page likes.

\subsection{Results Based on Facebook Usage}

Based on the research, it is surprising that the city of Szeged does not have a Facebook page, while Pécs only has a website that links to its various institutions, and they do not have a central page either. Of course, the social page of the city medium (the local news outlet if you like), has many followers in Szeged and Pécs, but they cannot be considered in the same category as the central Facebook pages of the other county seats. Interestingly, Tatabánya’s website included a Facebook link that linked to a non-operating page, but their Facebook page was eventually found. 
Table 2. Results - Facebook

\begin{tabular}{lrlrlc}
\hline \multicolumn{2}{c}{ Based on page likes } & \multicolumn{2}{c}{ Based on score (max. 30) } & \multicolumn{2}{c}{ Based on activity rate } \\
\hline City & Page Likes & City & Score & City & Activity rate \\
\hline Nyíregyháza & 30075 & Gyór & 24.0 & Kaposvár & $1.74 \%$ \\
\hline Székesfehérvár & 25449 & Debrecen & 23.0 & Szombathely & $1.74 \%$ \\
\hline Győr & 20635 & Székesfehérvár & 22.0 & Salgótarján & $1.15 \%$ \\
\hline Debrecen & 17743 & Szombathely & 21.0 & Tatabánya & $0.81 \%$ \\
\hline Kaposvár & 17167 & Szolnok & 20.5 & Zalaegerszeg & $0.75 \%$ \\
\hline Zalaegerszeg & 11410 & Kecskemét & 17.5 & Veszprém & $0.57 \%$ \\
\hline Eger & 10203 & Zalaegerszeg & 17.5 & Békéscsaba & $0.46 \%$ \\
\hline Szolnok & 10029 & Miskolc & 16.0 & Székesfehérvár & $0.44 \%$ \\
\hline Tatabánya & 8549 & Tatabánya & 16.0 & Debrecen & $0.43 \%$ \\
\hline Szombathely & 8242 & Kaposvár & 15.0 & Kecskemét & $0.43 \%$ \\
\hline Veszprém & 6812 & Eger & 14.5 & Szolnok & $0.32 \%$ \\
\hline Salgótarján & 5396 & Békéscsaba & 14.0 & Győr & $0.22 \%$ \\
\hline Békéscsaba & 4604 & Nyíregyháza & 14.0 & Miskolc & $0.21 \%$ \\
\hline Kecskemét & 2537 & Salgótarján & 14.0 & Eger & $0.12 \%$ \\
\hline Szekszárd & 2443 & Veszprém & 13.0 & Nyíregyháza & $0.10 \%$ \\
\hline Miskolc & 946 & Szekszárd & 9.0 & Szekszárd & $0.04 \%$ \\
\hline
\end{tabular}

In this part of the study, cities were ranked according to three criteria: the number and activity of their page visitors and their result in the scoring system. In terms of page views, Nyíregyháza and Székesfehérvár were the clear leaders with a follower base of over 30000 and 25000 respectively. Győr, Debrecen, and Kaposvár were also among the top cities. Miskolc came in last, well behind the other cities in the ranking. Meanwhile, it is important to point out that the ranking refers to the official Facebook page managed by the cities and that there may be several other profiles linked to a city, which may produce higher numbers. Moreover, while social media activity may be weaker, other means of digital, online communication can still be strong - for example, the website miskolc.hu won the Website of the Year prize of the Hungarian Marketing Association in 2018.

The activity rate is an indicator of the average percentage of fans who show activity in connection with the posts. This shows that Nyíregyháza, which performed best in the page engagement ranking, is in second-to-last place here, which is also due to the fact that 8-10 posts are shared on their page per day, which is not good for the trend of activities, as no post can "ramp up" completely. Kaposvár and Szombathely are at the top of the list, but Kaposvár has more activity 
overall, as the city page also stands high in the page like ranking, so the activity rate indicates a much larger active follower base.

Based on our qualitative scoring system, Győr came first, Debrecen second, Székesfehérvár third, and Szekszárd finished at the bottom of the list. Out of the 16 city Facebook pages, only two pages had not modified their link and four used a profile image other than the city's coat of arms or logo. All of them had a cover image, but only Debrecen used the livelier video option. Almost everyone provided information in the About section, but in several cases this was incomplete. In addition, links to other social media platforms can be attached, but only 5 pages used this option. The Events tab option was used by all pages.

During the analysis, it was interesting to observe how each city managed its Facebook page, with some of them using it as a "news agency" and others as a bulletin board or community space. The regularity of post shares showed very mixed results: for example, Békéscsaba's page was practically stagnant between November and February, while Nyíregyháza's page had 884 posts in three months, which means 8-10 shares per day. The regularity of posts has been taken care of by almost all pages - although some have gone overboard and posted a lot of times in connection with the COVID-19 situation. Szekszárd's page was the one that stuck out the most (in a negative sense), as they shared only one post in the past quarter of the year, and this was also reflected in their activity rate.

In terms of the content of the posts, cities prefer to use the link post format - it directs users to the website. They are usually published as articles/news. In addition to link posts, informative posts were found on almost all pages, but Székesfehérvár cleverly designs them with uniform graphical elements and colours, which, if used regularly, can be easily noticed by users and can also enhance the overall quality of the page. In the case of Székesfehérvár, another interesting fact is that podcast episodes, i.e. audio clips, were also shared during the period under review, which is currently a unique solution in the marketing activities of cities and an increasingly popular form of content from the users' point of view.

Posts with video and image galleries were also abundant on the pages, and these appear to be popular forms of posting, which generally resulted in higher user activity. Székesfehérvár and Zalaegerszeg also launched video campaigns in which local city leaders and celebrities encourage users to get vaccinated against the coronavirus. While these videos provoked very divisive reactions, they also undoubtedly generated high levels of activity. Zalaegerszeg also ran a music video campaign during the examined period, in the first quarter of 2021.

In contrast, there were hardly any posts encouraging people to get active only six cities used it, and they did so rarely. In this category, we have included posts that attempted to elicit interaction from users. Examples of such solutions include games (Tell us what...; Which one do you think...?) where users can reply in comments, wherefore such solutions encourage users to vote or react in other 
ways. In addition to these, the criterion of taking advantage of opportunities was also considered - by which we mean trends and the use of other forms of Facebook posts -, and only two cities met this criterion.

The content, quality, and regularity of the posts were therefore very mixed on the pages studied. Some, for example, only shared link posts without accompanying text, while others wrote extremely long texts. The regularity of so-called mood posts also varied. Some cities used this form of content on a weekly basis, while others did not use it at all. In our opinion, it may be worthwhile to use this, as in all cases they resulted in an outstanding level of activity for the pages. In terms of activities, the mayors of Székesfehérvár, Szombathely, and Zalaegerszeg are also regularly featured on the page, taking part in various actions, in several cases making live broadcasts or video announcements. Although the mayor's presence can generate divisive opinions - especially if the message is politicized -, when examining them from the aspect of activities, these appearances generated high numbers in almost all cases.

Spelling was impeccable on all pages, and the majority also used the right amount of emoticons. However, only half of the cities react or reply to comments from users on a regular basis, leaving many questions unanswered. It is also interesting to note that in the case of Székesfehérvár, the mayor often did this through his own Facebook page.

\section{An Analysis of the Instagram Pages of County Seats}

\subsection{Presentation of the Analytical Framework}

Table 3. Analytical framework - Instagram

\begin{tabular}{lc}
\hline Criteria & Score \\
\hline Unique username set (link) & 1 \\
\hline Profile picture is the city's coat of arms, logo & 1 \\
\hline Bio is filled (partially/fully) & 2 \\
\hline Bio has link to website/most social networking sites & 1 \\
\hline $\begin{array}{l}\text { Post sharing (occasional: 1, 1 per week: 2, 2 per week: 3, 3+ per week: 4, } \\
\text { daily 3+: -1) }\end{array}$ & 4 \\
\hline Uses gallery images (sometimes/regular) & 2 \\
\hline Uses highlights & 1 \\
\hline Uses IGTV & 1 \\
\hline Activity posts (sometimes/regular) & 2 \\
\hline Video posts (sometimes/regular) & 2 \\
\hline
\end{tabular}




\begin{tabular}{lc}
\hline Criteria & Score \\
\hline Use of own images (sometimes/regular) & 2 \\
\hline Spelling & 1 \\
\hline Emoji use & 1 \\
\hline Hashtag use & 1 \\
\hline Hashtag use also in English & 1 \\
\hline Has its own hashtag (and uses it consistently) & 1 \\
\hline Community management & 1 \\
\hline Number of followers (end of month 3) & - \\
\hline Number of posts (3 months) & - \\
\hline Average likes per post & - \\
\hline Average number of comments per post & - \\
\hline Engagement rate (average) & 25 \\
\hline TOTAL
\end{tabular}

Regarding this platform, we also focused on the settings that are visible to the "outside world". Thus, we looked at the profile picture (it is also important to use the city's logo or emblem here) and the elements of the bio (description), that is, whether it contains a link to the website or other social media platforms, as well as an introductory text or a slogan. We then looked at the frequency of posts, just as in the Facebook analysis, scoring it from 1 to 4 . We then turned our attention to the content of the posts, where we also scored possible post types. Examples include galleries, highlights (unfortunately, we are not able to look at stories as they are only available for 24 hours), IGTV, activity-increasing posts, and sharing video/GIF content. The use of own images and the consistent use of spelling, emoticons, and hashtags (also in English) on this platform were also examined. We concluded the set of yes/no questions with a question examining regular responses to comments.

Finally, we looked at the numbers - that is, the number of followers, the number of posts published in the last 3 months, and the average number of likes, comments, and shares per post - to calculate the activity rate.

\subsection{Results Based on the Use of Instagram}

During the analysis of these platforms (as in the case of the analysis of Facebook pages), three rankings were established according to different criteria. The first one was based on the number of followers, with Győr in first place and Székesfehérvár in the second. These cities were ranked lower in terms of activity, as the high number of followers was not associated with a high level of activity in their case, 
while for pages with a small follower base, a lower volume of activity resulted in a higher rate. (To understand this, let us look at the example of Győr, where the $2.82 \%$ activity rate indicates more interactions in terms of volume than the $7.96 \%$ result of Zalaegerszeg, the city ranked first.) Based on the scoring system set up by us, Győr ranked first, with Székesfehérvár in the second place. Interestingly, Miskolc came third in terms of page likes, activity rate, and scoring alike.

Table 4. Results - Instagram

\begin{tabular}{lrlrlc}
\hline \multicolumn{2}{c}{ Based on followers } & \multicolumn{2}{c}{ Based on scoring } & \multicolumn{2}{c}{ Based on activity rate } \\
\hline City & Followers & City & Score & City & $\begin{array}{c}\text { Activity } \\
\text { rate }\end{array}$ \\
\hline Gyôr & 3512 & Gyór & 19.0 & Zalaegerszeg & $7.96 \%$ \\
\hline Székesfehérvár & 3250 & Székesfehérvár & 17.5 & Békéscsaba & $7.60 \%$ \\
\hline Miskolc & 2881 & Miskolc & 17.0 & Miskolc & $4.58 \%$ \\
\hline Nyíregyháza & 2655 & Kecskemét & 15.0 & Kaposvár & $3.45 \%$ \\
\hline Kaposvár & 1973 & Zalaegerszeg & 15.0 & Győr & $2.82 \%$ \\
\hline Debrecen & 1640 & Szombathely & 14.0 & Szombathely & $2.47 \%$ \\
\hline Békéscsaba & 1592 & Békéscsaba & 12.0 & Kecskemét & $2.34 \%$ \\
\hline Eger & 1259 & Debrecen & 12.0 & Debrecen & $2.32 \%$ \\
\hline Szombathely & 1051 & Kaposvár & 8.0 & Székesfehérvár & $2.25 \%$ \\
\hline Kecskemét & 556 & Nyíregyháza & 5.0 & Nyíregyháza & $0.00 \%$ \\
\hline Zalaegerszeg & 515 & Eger & 4.0 & Eger & $0.00 \%$ \\
\hline
\end{tabular}

As can be seen in the table, there are far fewer cities on Instagram, and many of the cities above are using the platform irregularly or have stopped posting. Békéscsaba's page was inactive between November and February (as was their Facebook platform). The pages of Zalaegerszeg and Eger became active after a one-year break, Debrecen restarted Instagram activities after a 5-month break, and Nyíregyháza's page has not had any posts since January 2020.

Győr, Miskolc, Székesfehérvár, and Szombathely are active users of Instagram, and they have not stopped posting regularly despite the virus situation. These pages often use gallery or video post types. The platforms of Székesfehérvár and Győr also convey a unified image through Highlights. In the case of Győr and Miskolc, their content posted on Instagram is also repeatedly posted on Facebook, which may not be the best content-posting strategy in the long run, as it is enough for the users to follow one platform because the other one does not provide anything new to them.

All but 3 cities chose a coat of arms or logo as their profile picture, and most pages filled in the bio appropriately, as almost all of the descriptions included a link to a website or other social media platform. 
On this platform, almost all cities tried to use their own pictures, but Kecskemét's page shared several creatives that were practically posters with lots of text. Although this is clearly visible on a monitor, it is not at all readable for mobile phone users, and there is no possibility to enlarge it properly on this platform. In addition, it should be noted that Instagram is mostly used as a mobile app, so it is worth paying special attention to the readability of the creatives here.

All but a few pages used hashtags for their posts, but these were mostly in Hungarian, with only five pages using labels in English. Six pages also used their own hashtags, which were consistently displayed in the majority of their posts and the bio. Although we gave extra points for comment management, this was not necessary for any of the pages, as users did not really comment in text; most of them provided feedback in the form of emoticons.

\section{An Analysis of the YouTube Channels of County Seats}

\subsection{Presentation of the Analytical Framework}

Table 5. Analytical framework - YouTube

\begin{tabular}{lc}
\hline Criteria & Score \\
\hline Unique user URL set & 1 \\
\hline Profile picture is the city's coat of arms, logo & 1 \\
\hline Has a cover photo & 1 \\
\hline There are links to other social media channels & 1 \\
\hline Contact data are filled in & 1 \\
\hline Frequency of videos (irregular: 1, monthly: 2, 2 per month: 3, 1 per week/more: 4$)$ & 4 \\
\hline Has at least 1 playlist & 1 \\
\hline Has posts under the community tab & 1 \\
\hline High-quality videos & 1 \\
\hline Has video description & 1 \\
\hline Uses consistent index images & 1 \\
\hline Community management & 1 \\
\hline Number of subscribers (end of month 3) & - \\
\hline Number of videos (3 monthly) & - \\
\hline Average number of views/video & - \\
\hline Average number of likes/video & - \\
\hline Average number of dislikes/video & - \\
\hline Average number of comments/video & - \\
\hline TOTAL & 15 \\
\hline
\end{tabular}


The link can also be modified on YouTube, which can be changed if the city has enough followers. It is also recommended to set the city's coat of arms or logo as the profile picture, and the cities can also upload a cover image and set buttons linking to other social media platforms. It is also useful to fill in the About details on this platform to inform users.

We examined the use of other features such as the creation of playlists (at least one) or posts that could be published under the social tab, and then scored the regularity of posting videos, which was given a score of up to four points depending on whether video content was published irregularly, monthly, fortnightly, weekly, or more often. We then looked at the quality of the videos, whether there was a description added, whether the index images were consistent, and whether the comments received were replied on behalf of the page.

Finally, we also summarized the numbers on this platform, including subscribers, videos posted in the last three months, and average views, likes, dislikes, and comments per video.

\subsection{Results regarding the Use of YouTube}

Table 6. Results - YouTube

\begin{tabular}{lclclc}
\hline \multicolumn{2}{c}{ Based on subscribers } & \multicolumn{2}{c}{ Based on scoring } & \multicolumn{2}{c}{ Based on average video views } \\
\hline City & Subscribers & City & Score & City & Video views \\
\hline Székesfehérvár & 1240 & Székesfehérvár & 11.0 & Debrecen & 1158 \\
\hline Debrecen & 237 & Tatabánya & 9.0 & Veszprém & 937 \\
\hline Tatabánya & 212 & Veszprém & 7.0 & Gyór & 254 \\
\hline Zalaegerszeg & 78 & Győr & 6.5 & Székesfehérvár & 208 \\
\hline Szombathely & 74 & Debrecen & 6.0 & Békéscsaba & 184 \\
\hline Kecskemét & 55 & Kecskemét & 5.0 & Tatabánya & 97 \\
\hline Szekszárd & 51 & Miskolc & 4.0 & Kecskemét & 76 \\
\hline Miskolc & 39 & Békéscsaba & 3.0 & Miskolc & 37 \\
\hline Veszprém & 30 & Zalaegerszeg & 1.0 & Szombathely & 0 \\
\hline Békéscsaba & 18 & Szekszárd & 1.0 & Zalaegerszeg & 0 \\
\hline Győr & 8 & Szombathely & 0.0 & Szekszárd & 0 \\
\hline
\end{tabular}

In many cases, YouTube channels were difficult to find, as in certain cases they were not listed on the search results page or websites and other social media platforms where they could be clicked through. A total of 11 channels were found, again ranked in three different ways. In terms of subscribers, Székesfehérvár topped the list, standing out from the rest, while Győr came last. In terms of video views, 
Debrecen stood out from the platforms examined. Based on the points received, Székesfehérvár was ranked first, Tatabánya was second, and Veszprém third. Győr, in fourth place in the ranking, makes the most of its opportunities, but it has very few subscribers.

Szekszárd, Szombathely, and Zalaegerszeg had no videos uploaded to their channels during the examined period, while Székesfehérvár and Tatabánya shared 9 videos in the first quarter of 2021.

The profile picture of the channel was appropriately set up in six cities, but only four cities uploaded a cover image, and only Székesfehérvár and Veszprém used the channel to redirect to other social media platforms. At least one playlist was found on seven channels, but only Székesfehérvár used the Social tab. In general, the published videos were of good quality and most of them were accompanied by a video description, but none of the channels used a uniform index image.

Some cities have turned off the possibility of commenting, which is not necessarily a good decision as it completely cuts off user feedback even though one of the essential features of online presence is mutual communication.

\section{Experiences and Recommendations Based on the Social Media Communication of the County Seats}

The above study shows that the majority of cities are trying to maintain an active presence on Facebook, with varying degrees of success. In contrast to the default settings, we could discover several interesting contrasts in post types (e.g. lots of text without pictures or little text with pictures), all of which were popular or none of them. Generally speaking, thoughtful, regular, and activity-stimulating posting, as well as a diversity of content and two-way communication with users can be a good way forward. The challenge for social media communication is to provide users with content that is fresh, interesting, and informative on a daily basis (that is also thoughtful in terms of marketing strategy), which also encourages user activity.

Instagram is used regularly by significantly fewer cities. This platform has a lot of potential, not only for young people but also for foreign and domestic tourists, as it is generally considered that the Instagram platform has a much higher activity rate than Facebook. It may therefore be worthwhile to publish 2-3 posts a week on the platform (even thematically) so that people can find the city on this platform - but, unlike Facebook, they will find a different type of content, as the former is mainly about informing, while the latter is more about image building. It is therefore advisable not to duplicate content but rather to regularly publish posts made for the specific platform with smaller frequency. 
Creating content on YouTube requires more effort and work because while a Facebook or Instagram post can be put together - with a little exaggeration - by just about any marketing person, the shooting and post-production of videos usually requires an expert and the right tools for video production (which is usually not a low-cost process), so it is recommended to hire a specialized team for this. In addition, it is more difficult to determine which direction to take on this platform besides the usual image videos and promotional content. The research showed that most cities are not actively using their channel, and if they are uploading some content, it is likely to have been created for another platform or for advertising purposes. However, even on this platform it is worth experimenting, trying out different directions, whether it is a live broadcast from the mayor or a recording of a typical weekday representing the atmosphere or an interview with a local celebrity.

LinkedIn, Twitter, Snapchat, and TikTok were not included in the survey, as these platforms are actively used by very few cities or none of them. However, it may be worth considering them when planning online marketing activities, as each of them allows cities to reach a different target group (e.g. LinkedIn reaches investors and TikTok reaches very young people). However, it should also be remembered that the quality of content on all platforms must be kept in mind, so it is not worth launching a new platform if you do not have the appropriate resources or ideas.

All in all, it can be concluded that social media marketing has a prominent role in city marketing and city communication. However, there is plenty of room for improvement, even in the case of large cities, as only 16 of the 18 county seats surveyed had their own Facebook pages, 11 had Instagram profiles, and 11 had YouTube channels - and these were also active at varying levels. Nevertheless, the cities at the top of the rankings set a good example. It is not only the other county seats that should learn from them but also all other cities and even villages, as online competition between settlements is likely to increase in the coming period. The criteria set out in the study can provide a checklist of things to look out for when using Facebook, Instagram, and YouTube.

\section{References}

Gary, J., 2019. Instagram Marketing. Private publication.

Klausz, M. (2011). Facebook, YouTube, Wikipedia and Others... Social Media in the Corporate Environment. Vol. 2, extended edition. Veszprém: private publication. Mohsin, M. (2021a). 10 Snapchat Statistics You Need to Know in 2021 (Infographic) in Oberlo. Retrieved from oberlo.com: <https://www.oberlo.com/blog/snapchatstatistics $>$ [Accessed on 11 November 2021]. 
2021b. 10 TikTok Statistics That You Need to Know in 2021 (Infographic) in Oberlo. Retrieved from oberlo.com: <https://www.oberlo.com/blog/tiktokstatistics $>$ [Accessed on 11 November 2021].

Newberry, C. (2021a). 25 YouTube Statistics That May Surprise You: 2021 Edition. Retrieved from hootsuite.com: <https://blog.hootsuite.com/youtube-statsmarketers/> [Accessed on 11 November 2021].

(2021b). 44 Instagram Stats That Matter to Marketers in 2021. Retrieved from hootsuite.com: <https://blog.hootsuite.com/instagram-statistics/> [Accessed on 11 November 2021].

(2021c). 47 Facebook Stats That Matter to Marketers in 2021. Retrieved from hootsuite.com: <https://blog.hootsuite.com/facebook-statistics/> [Accessed on 11 November 2021].

\section{Cite as:}

Papp-Váry, Á.-Kiss-Szűcs, A. (2021). The Social Media Communication of Hungarian County Seats: Facebook, Instagram, and YouTube Presence. Acta Universitatis Sapientiae, Communicatio 8: 84-103. DOI: 10.2478/auscom-2021-0007. 